\title{
Foliar Application of Abscisic Acid Increases Freezing Tolerance of Field-Grown Vitis vinifera Cabernet franc Grapevines
}

\author{
Yi Zhang ${ }^{1}$ and Imed E. Dami ${ }^{2 *}$
}

\begin{abstract}
The purpose of this study was to develop a method to increase freezing tolerance of field-grown grapevines using foliar application of abscisic acid (ABA). The specific objectives were to evaluate the morphological and physiological changes of field-grown Vitis vinifera Cabernet franc grapevines in response to exogenous ABA application and to determine an optimum timing for foliar application of ABA that results in enhanced freezing tolerance. Cabernet franc grapevines grown at two locations were treated with 400 and $600 \mathrm{mg} / \mathrm{L}$ ABA at different stages of development corresponding to veraison and 20,30, 40, and 55 days postveraison. ABA did not affect yield components or basic fruit chemical composition. However, it enhanced anthocyanin concentration, advanced dormancy, decreased bud water content, and ultimately increased freezing tolerance under simulated freezing events. The increased freezing tolerance by ABA was confirmed by assessing bud injury following natural freezing events of $-19^{\circ} \mathrm{C}$ and $-23^{\circ} \mathrm{C}$ in two locations. The effectiveness of ABA may have been enhanced by application timing, which was optimum at veraison and 20 to 30 days postveraison. Results suggest that ABA application has the capacity to enhance dormancy and increase freezing tolerance and can be used as a prophylactic tool to protect against winter injury of grape cultivars grown in cold regions.
\end{abstract}

Key words: anthocyanin, bud injury, cold hardiness, dormancy, leaf senescence, periderm formation, water content

Grape and wine industries in colder regions of the United States have been expanding. The winegrape cultivars that currently dominate the market in acreage and production of premium wines and are therefore desired by grape and wine producers are derived from the species Vitis vinifera. Currently more than $80 \%$ of grape expansion in Ohio is planted with cold-sensitive cultivars of $V$. vinifera (Dami, author's personal data). Unfortunately, these cultivars have moderate to low freezing tolerance and are sensitive to freezing temperatures below $-20^{\circ} \mathrm{C}$. These $V$. vinifera cultivars are more susceptible to winter injury than their native counterparts that are traditionally grown in these regions (Zabadal et al. 2007). The severe winters in the eastern U.S. can lead to significant economic losses in grape production by substantially decreasing yield and fruit composition and increasing cost of production due to retraining and replacing injured or

${ }^{1}$ Graduate Research Associate, ${ }^{2}$ Associate Professor, Department of Horticulture and Crop Science, The Ohio State University, Ohio Agricultural Research and Development Center, 1680 Madison Ave., Wooster, OH 44691.

*Corresponding author (email: dami.1@osu.edu)

Acknowledgments: Financial support was provided by the Department of Horticulture and Crop Science, OARDC/OSU, and the Lonz Foundation. The ABA sample was provided by Valent Biosciences (Libertyville, IL).

The authors thank Trudi Grant for technical assistance with sugar analysis, Joe Scheerens and Ann Chanon for assistance with anthocyanin analysis, and Bruce Williams and Greg Johns for maintaining the research vineyards in Wooster and Kingsville, respectively.

Manuscript submitted Jan 2012, revised Mar 2012, accepted Apr 2012

Copyright (C) 2012 by the American Society for Enology and Viticulture. All rights reserved.

doi: 10.5344/ajev.2012.12006 dead vines (Zabadal et al. 2007). In the northeast U.S. and in Ontario, Canada, there have been frequent crop losses in the last decade, with notable freezing events in 2003, 2004, and 2005 (Zabadal et al. 2007). In Ohio, there were major consecutive freezing-related grape losses in the last five years; losses in 2009 were the heaviest (Dami et al. 2012). The expansion of grape acreage and the success and sustainability of the grape and wine industries in cold regions is limited by the constraints of the occurrence and frequency of freezing stress.

To alleviate the impact of freezing stress on grapevines, several freeze protection methods have been developed with the purpose of either changing vineyard microclimate conditions or improving the freezing tolerance of grapevines. Both active and passive freeze protection methods have been developed for grapevines. Active protection methods include wind machines, heaters, and over-vine sprinkling (Poling 2007). Passive methods include site and variety selection (Zabadal et al. 2007) and application of chemical protectants (Dami and Beam 2004). Among chemicals, growth regulators such as abscisic acid (ABA) have been applied in order to increase freezing tolerance in crops, including Secale cereale L. (Churchill et al. 1998) and Malus domestica (L.) Borkh. (Guak and Fuchigami 2001).

$\mathrm{ABA}$ is a plant hormone that plays an important role in plants acquiring cold hardiness. In grape, three unique Crepeat/DRE binding factor genes have been shown to respond to low temperature and $\mathrm{ABA}$, providing evidence of a connection between freezing tolerance development and $\mathrm{ABA}$ in grapevines at the genomic level (Xiao et al. 2006). Additionally, in Arabidopsis thaliana, a freezing sensitive mutant was developed and proved to be a new aba3 allele (Llorente et al. 
2000), indicating that the mutant plant, which is insensitive to ABA, has a lower freezing tolerance compared to normal plants. One method of increasing the freezing tolerance of plants is to dehydrate them to reduce the intracellular water and avoid ice formation. ABA-treated plants with increased cold tolerance had lower relative leaf water content than untreated control plants (Kumar et al. 2008). Exogenous application of ABA to grapes has also been investigated to delay budburst for spring frost protection, but was not effective on field-grown grapevines (Hellman et al. 2006). ABA has also been used on table grapes to enhance color development and advance fruit maturity (Peppi et al. 2007). ABA induced growth recession, leaf abscission, and increased periderm formation in greenhouse-grown grapevines; such changes are typically associated with dormancy and cold acclimation (Zhang et al. 2011). However, to our knowledge, there are no published reports on the effect of exogenous ABA on the freezing tolerance of field-grown winegrapes. The purpose of this study was to investigate the influence of foliar application of ABA on freezing tolerance of Vitis vinifera Cabernet franc, a popular but moderately cold-sensitive cultivar planted extensively in the eastern United States. We hypothesized that ABA would induce morphological and physiological changes in grapevines that would ultimately lead to increased freezing tolerance. The specific objectives were to evaluate the morphological and physiological changes of field-grown grapevines Vitis vinifera Cabernet franc grapevines in response to exogenous ABA application and to determine the optimum timing of foliar application of ABA that results in enhanced freezing tolerance.

\section{Materials and Methods}

Plant material, experimental design, and treatments. Vitis vinifera Cabernet franc (clone 1) grafted on V. riparia $\times V$. rupestris Couderc 3309 rootstock were planted in 2005 at the Research Vineyard in Wooster, OH. Vines were spaced $1.8 \times 2.4 \mathrm{~m}$ (vine $\times$ row), trained to a bilateral cordon system with vertical shoot-positioning, and spur-pruned to 16 buds $/ \mathrm{m}$ of cordon. In 2009, four treatments were assigned to vines on a randomized complete block consisting of five blocks with 10 vines each as follows: control $(0 \mathrm{mg} / \mathrm{L} \mathrm{ABA}$, sprayed only with deionized water and $0.05 \%$ surfactant $), \mathrm{V}(400 \mathrm{mg} / \mathrm{L}$ ABA sprayed at $50 \%$ veraison), V30 (400 mg/L ABA sprayed 30 days after veraison), and $\mathrm{V}+\mathrm{V} 30$ (multiple applications of $400 \mathrm{mg} / \mathrm{L} \mathrm{ABA}$ at veraison and 30 days later). Canopy management practices consisted of leaf removal of the basal three leaves on both sides of the canopy in late July followed by cluster thinning to $\sim 25$ clusters per vine. Shoot hedging was performed on all vines in early August.

This experiment was repeated in 2010 at Wooster with the following treatments: control (same as above), V (400 mg/L ABA sprayed at $50 \%$ veraison), V20 (400 mg/L ABA sprayed at 20 days after $50 \%$ veraison), and V40 (400 mg/L ABA sprayed at 40 days after $50 \%$ veraison). In addition to the experiments in Wooster, a second location was used in 2010 at the Ashtabula Agricultural Research Station, Kingsville, $\mathrm{OH}$. Cabernet franc (clone 1) grafted on $V$. riparia $\times V$. rup- estris 101-14 Millardet et de Grasset rootstock were planted in 2005. Vine spacing, training, and pruning were the same as the Cabernet franc vines grown in Wooster. The vineyard block was divided into four blocks. Each block consisted of 20 grapevines, which were divided into five panels (four vines per panel). Each panel was randomly assigned to one of five treatments: control (same as above) or $600 \mathrm{mg} / \mathrm{L} \mathrm{ABA}$ sprayed at V, V20, V40, or V55 (20, 40, or 55 days after $50 \%$ veraison). In each panel, the first three vines were used as a replicate for one treatment and the fourth was an untreated buffer vine. Canopy management practices were similar to those conducted in Wooster except for cluster thinning. A spring frost event $\left(-1.2^{\circ} \mathrm{C}\right)$ occurred on 10 May 2010 , causing injury to shoots and inflorescences and resulting in an uneven number of clusters per vine. To avoid the potential confounding effect of crop level, the shoot number per vine was adjusted and all clusters were dropped from all treated vines.

The ABA sample (VBC-30051; Valent Bioscience, Libertyville, IL) had an a.i. of $20.0 \%(\mathrm{w} / \mathrm{w})$ S-ABA. The ABA sample was dissolved in deionized water with $0.05 \%$ Tween-20 (Acros Organic, Hampton, NH). Whole vine canopies (leaves and clusters) were sprayed with ABA solutions to runoff with a 15 L back sprayer (model SP0; SP System LLC, Santa Monica, CA) averaging a spray volume of $0.5 \mathrm{~L} / v i n e$.

Yield components. Yield components, including crop weight per vine, cluster number/vine, and weight of 100 berries, were collected both years. Cluster weight was computed based on crop weight per vine divided by cluster number per vine. In Wooster, grapes were harvested on 6 Oct 2009 and 27 Sept 2010. In Kingsville, there was no harvest due to the spring frost and crop removal.

Basic juice analysis. In 2009, a 100-berry sample was collected from each replicate biweekly from veraison through harvest to determine soluble solids, titratable acidity (TA), and $\mathrm{pH}$. In 2010, the 100-berry sample was only collected at harvest. Berries were weighed using an electronic scale (Denver Instrument, Bohemia, NY), and then the berry samples were juiced at room temperature. The juice was transferred to a $50-\mathrm{mL}$ centrifuge tube and centrifuged at $8500 \mathrm{rpm}$ for 5 min (accuSpin 400; Fisher Scientific, Pittsburgh, PA). After centrifugation, a $10 \mathrm{~mL}$ supernatant was transferred to a $\mathrm{pH} /$ EP titration work station (model 350/352 with SAC80 sample changer; Denver Instrument) to measure $\mathrm{pH}$ and TA. TA was determined by titrating the $10 \mathrm{~mL}$ aliquot of juice sample to a pH 8.2 with $0.1 \mathrm{~N} \mathrm{NaOH}$. Soluble solids were measured with a digital refractometer (MISCO, Cleveland, $\mathrm{OH}$ ) and expressed in Brix.

Anthocyanin analysis. At harvest, a 50-berry sample was collected from each replicate and frozen at $-20^{\circ} \mathrm{C}$ until analysis. Berries were thawed at room temperature and then crushed into slurry using a hand blender (Whirlpool, Benton Charter Township, MI). Approximately $2 \mathrm{~g}$ slurry was placed into a $50 \mathrm{~mL}$ centrifuge tube (Fisher Scientific) containing 40 $\mathrm{mL}$ of $1 \% \mathrm{HCl}$ acidified methanol (Fisher Scientific) extraction solvent. Slurry suspensions were allowed to extract for $1 \mathrm{hr}$ at room temperature. Suspensions were then centrifuged for $15 \mathrm{~min}$ at 15,000 rpm and the supernatant was transferred 
into a $100 \mathrm{~mL}$ volumetric flask (Normax, New Milford, CT). The pellet was re-extracted using the procedure described above, and then a third extraction was completed in $30 \mathrm{~min}$ using $15 \mathrm{~mL} \mathrm{1 \%} \mathrm{HCl}$ acidified methanol. The solution was brought to volume with $1 \% \mathrm{HCl}$ acidified methanol and equilibrated by inversion of the flask twice. One $\mathrm{mL}$ extract was diluted by the addition of $4 \mathrm{~mL} 1 \% \mathrm{HCl}$ acidified methanol; the absorbance of the diluted solution was measured using a spectrophotometer (DU730; Beckman Coulter, Brea, CA) at $520 \mathrm{~nm}$, the wavelength of maximum absorbance. In 2010, anthocyanin measurement was conducted for the skins only since most anthocyanin is located in berry skins (Jeong et al. 2004). A freeze-dry method was used to facilitate anthocyanin extraction (Ju and Howard 2003). Thus, anthocyanin concentration was expressed in $\mathrm{mg} / \mathrm{g}$ skin DW. For that purpose, the berry skins were manually separated from fleshy fruit tissues and freeze-dried using a lyophilizer (Labconco Corp. Kansas City, MO). The extraction procedure followed the same protocol as in 2009 except the dilution ratio was 1:20 for the absorbance measurement at the last step. The molar absorptivity of anthocyanin was reported by Giusti et al. (1999). The anthocyanin content was expressed in $\mathrm{mg} / \mathrm{g}$ and calculated as absorbance molar absorptivity $(\mathrm{mol} / \mathrm{L}) *$ molecular weight $(\mathrm{g} / \mathrm{mol}) *$ dilution ratio $(1: 5$ in Year $1,1: 20$ in Year 2) * $0.1 \mathrm{~L} * 1000(\mathrm{mg} / \mathrm{g}) /$ sample weight $(\mathrm{g})$.

Periderm formation and leaf senescence. Periderm formation was determined by counting shoot internodes that changed color from green to tan or brown. Two shoots were tagged per replicate and the numbers of lignified internodes and total internodes were recorded. The evaluation was conducted once a week from mid-August until all shoots were $100 \%$ lignified in Wooster. In Kingsville, the evaluation was conducted on 31 Aug, 16 Sept, 11 Oct, and 25 Oct 2010. Periderm formation was expressed as the ratio of number of brown to total number of internodes per shoot.

Leaf senescence was assessed by monitoring chlorophyll content, which was measured using a SPAD-520 chlorophyll meter (Spectrum Technologies, East Plainfield, IL). Five random measurements were taken on the upper surface of the fifth basal leaf on two shoots per replicate. Measurements were recorded weekly in Wooster from early September (post-ABA application) through October 2009 (harvest) and biweekly in Kingsville from August through October 2010.

Bud dormancy. Bud dormancy assays were conducted monthly in Wooster in 2009-2010 and 2010-2011 and in Kingsville in 2010-2011. Results of the 2010-2011 season are presented from both locations. Two representative 1-yrold canes with a minimum of 12 to 15 lignified internodes were collected from each replication, and buds on node positions 3 to 7 from each cane were used in the assay. In total, there were 10 nodes in each replication. Lignified shoots with periderm formation from the base were excised into one-node cuttings $\sim 5 \mathrm{~cm}$ long, then inserted into $2.5 \mathrm{~cm} \times 2.5 \mathrm{~cm}$ foam medium (Smithers-Oasis, Kent, $\mathrm{OH}$ ) and placed in $55 \mathrm{~cm} \times 25$ $\mathrm{cm} \times 7 \mathrm{~cm}$ plastic trays (T.O. Plastics, Clearwater, MN) filled with water. The bud dormancy assay followed a previous protocol (Zhang et al. 2011). Budburst was recorded as E-L stage
5 (Eichhorn and Lorenz 1977) and monitored three times a week for 30 days. Dormancy was estimated as the number of days to $50 \%$ budburst (D50BB). The higher D50BB, the more buds are dormant (Wake and Fennell 2000).

Determination of freezing tolerance. One representative 1-yr-old cane with a minimum of 12 to 15 lignified internodes was collected from each replication and buds on node positions 3 to 7 were used. There were five buds used from each replication and 25 and 20 buds per treatment in Wooster and Kingsville, respectively. Buds were excised and mounted on thermoelectric modules (Melcor, Trenton, NJ), which were placed in a Tenney environmental chamber (Thermal Products Solutions, New Columbia, PA). The Tenney temperature was lowered from -2 to $-50^{\circ} \mathrm{C}$ at $4^{\circ} \mathrm{C} / \mathrm{hr}$. Freezing tolerance of buds was determined using thermal analysis and was expressed as the average lethal temperature exotherm that kills $50 \%$ of the population, or LT50 (Wolf and Pool 1987). In Wooster, LT50s were determined six times from September 2009 to March 2010 and then repeated from October 2010 to February 2011. In Kingsville, LT50s were determined six times from October 2010 to January 2011.

On 22 and 24 Jan 2011, air temperatures dropped to $-19^{\circ} \mathrm{C}$ in Wooster and $-23^{\circ} \mathrm{C}$ in Kingsville, respectively. The minimum temperatures recorded were near the LT50 values determined on 15 and 18 Jan 2011 in Kingsville and Wooster, respectively. Therefore, a bud injury assessment of Cabernet franc grapevines was conducted. Ten canes with 10 buds (node positions 3 to 12) per replicate were collected from all treatments in both locations after the freezing events in late January 2011. Canes were thawed overnight, buds were excised with a razor blade, and primary buds were visually assessed as either alive (green) or dead (brown). Winter injury was expressed as a percent of injured primary buds.

Bud water content. Since many vines were available, which allowed for frequent sampling, bud water content was determined in Kingsville only. One cane was collected from each replication $24 \mathrm{hr}$ after ABA application from August to October and then at the same frequency as the freezing test. The shoots were transported to Wooster in a cooler filled with ice. Buds on node positions 3 to 7 of each shoot were excised and weighed before and after placing in an oven at $70^{\circ} \mathrm{C}$. Water content was expressed as percent of fresh weight.

Statistical analysis. All data were subjected to one-way analysis of variance using Minitab statistical software (Minitab, State College, PA). The model tested for main effects of different treatments. When appropriate, means were separated using LSD ( $\alpha=0.05)$. The correlation between bud cold hardiness and water content was explored by applying Pearson correlation analysis with Minitab statistical software (ver. 16; Minitab Inc., State College, PA).

\section{Results}

Based on previous greenhouse work, it was determined that $\mathrm{ABA}$ rates of 400 to $600 \mathrm{mg} / \mathrm{L}$ were not phytotoxic to Cabernet franc grapevines (Zhang et al. 2011). Consequently, these rates were applied to field-grown grapevines. Overall, phytotoxicity results of field-grown grapevines were similar to 
those from the greenhouse study. With the exception of minimum leaf damage incidence in field-grown Cabernet franc $(<6 \%$ affected leaf area) there was no effect among all ABA treatments on time of budburst or bud fruitfulness (carryover effect) in the following season (data not shown). Therefore, it was concluded that 400 or $600 \mathrm{mg} / \mathrm{L} \mathrm{ABA}$ was optimum for foliar application and these concentrations were used for further experiments.

Yield components and fruit composition. ABA treatment did not affect yield components of Cabernet franc grapevines during the course of this study. The cluster number per vine was maintained between 21 and 27. The ranges of cluster weight, 100-berry weight, and yield per vine were 95 to 121 $\mathrm{g}, 155$ to $177 \mathrm{~g}$, and 2.2 to $3.2 \mathrm{~kg}$, respectively. There were no differences among treatments in any yield component.

In 2009, the biweekly 100-berry sampling showed that fruit ripening progression was not affected by ABA treatment, as there were no differences in soluble solids, $\mathrm{pH}$, or TA among treatments on each collection (data not shown). At harvest, there was no difference in fruit chemical composition among treatments except for $\mathrm{pH}$ in 2010 (Table 1). In 2009, $\mathrm{ABA}$ application at $\mathrm{V}$ and $\mathrm{V} 30$ increased anthocyanin concentration by $17 \%$ compared to control grapevines. In 2010, ABA treatment at V40 increased anthocyanin concentration by $15 \%$ compared to the control.

Periderm formation and leaf senescence. No difference of periderm formation among treatments was observed during the course of the study. All Cabernet franc grapevines started to lignify in mid-August, which corresponded to veraison during which ABA treatments were applied, and reached $90 \%$ lignification within three weeks. At Wooster, all treatments exhibited a similar trend of chlorophyll content, which was

Table 1 Effect of ABA on fruit composition in Cabernet franc grapevines grown in Wooster, 2009 and 2010.

\begin{tabular}{lccccc}
\hline Harvest date & Treatment & Brix & pH & $\begin{array}{c}\text { Titratable } \\
\text { acidity } \\
\text { (g/L) }\end{array}$ & $\begin{array}{c}\text { Total } \\
\text { anthocyanin }\end{array}$ \\
\hline 6 Oct 2009 & & & & & $\begin{array}{c}\text { Whole berry } \\
\text { (mg/g FW) }\end{array}$ \\
& Control & 22.0 & 3.45 & 6.6 & $0.98 \mathrm{~b}^{\mathrm{c}}$ \\
& $\mathrm{V}$ & 22.1 & 3.47 & 6.5 & $1.14 \mathrm{a}$ \\
& $\mathrm{V} 30$ & 22.0 & 3.46 & 6.6 & $1.16 \mathrm{a}$ \\
& $\mathrm{V}+\mathrm{V} 30$ & 22.1 & 3.47 & 6.5 & $1.10 \mathrm{ab}$ \\
& Signf & $\mathrm{ns}$ & $\mathrm{ns}$ & $\mathrm{ns}$ & $*$ \\
& & & & & $\begin{array}{c}\text { Berry skin } \\
\text { (mg/g DW) }\end{array}$ \\
& & & & & $26 \mathrm{~b}$ \\
& Control & 22.6 & $3.75 \mathrm{a}$ & 3.4 & $28 \mathrm{ab}$ \\
& $\mathrm{V}$ & 22.5 & $3.73 \mathrm{ab}$ & 3.3 & $26 \mathrm{~b}$ \\
& V20 & 22.4 & $3.72 \mathrm{ab}$ & 3.3 & $30 \mathrm{a}$ \\
& V40 & 22.7 & $3.66 \mathrm{~b}$ & 3.1 & $*$ \\
& Signf & $\mathrm{ns}$ & $*$ & $\mathrm{~ns}$ & $*$
\end{tabular}

a, V20, V30, V40: ABA sprayed at $50 \%$ veraison, 20,30 , and 40 days after $50 \%$ veraison, respectively. $\mathrm{V}+\mathrm{V} 30$ : $A B A$ sprayed at $\mathrm{V}$ and V30 stages.

${ }^{b *},{ }^{* *},{ }^{* * *}$, and ns indicate significance at $p \leq 0.05,0.01$, and 0.001 , and not significant, respectively.

'Means followed by different letters in columns are significantly different at $p \leq 0.05$ using LSD. steady in September, decreased by $\sim 30 \%$ on 13 Oct 2009 , and continued to decrease linearly until the last measurement (Figure 1A). At Kingsville, the same observations were made: steady chlorophyll content in August through September followed by a reduction of $\sim 30 \%$ on 25 Oct 2010 (Figure 1B). Furthermore, the postveraison treatments (V20 in 2010 at Kingsville and V30 in 2009 at Wooster) consistently reduced the chlorophyll content compared to the controls. In late fall, leaves on ABA-treated grapevines abscised two weeks earlier than those on control vines in both years.

Bud dormancy. Under the forcing conditions and dormancy protocol used, D50BB ranged between 23 and 34 in Wooster and 19 and 34 in Kingsville, indicating that vines already entered dormancy. Nondormant vines typically have D50BB values $<10$ (Zhang et al. 2011). At Wooster, D50BB values were the same in October; however, there were differences between ABA-treated and control vines from later collections. Specifically, budburst of V and V20 ABA-treated vines was delayed by an average of four days from November through February (Figure 2A). The delay of budburst between ABA-treated and control vines indicated that the former entered a deeper dormancy status than the latter. A similar observation was made at Kingsville, with the V20
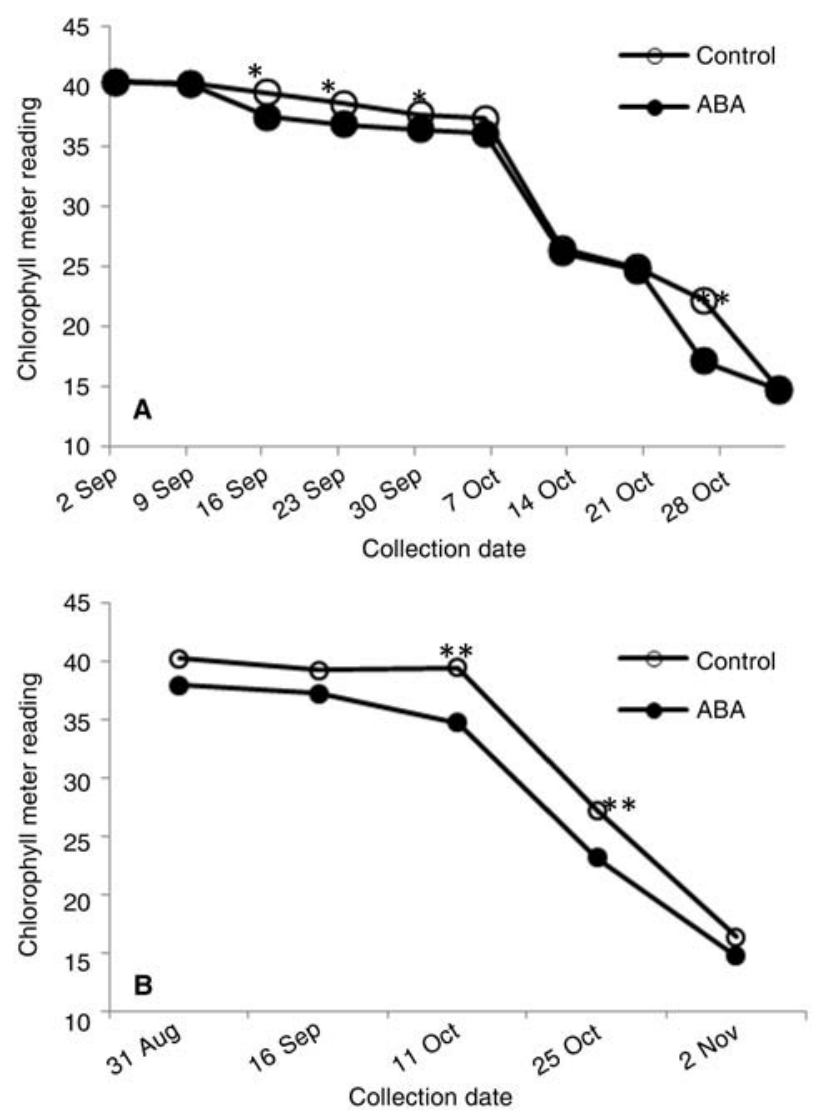

Figure 1 Chlorophyll content progression in ABA-treated and untreated Cabernet franc grapevines grown at (A) Wooster (2009) and (B) Kingsville (2010). For clarity, only one ABA plot was presented, which is V30 treatment in (A) and V20 treatment in (B) and corresponds to ABA application at 30 and 20 days after $50 \%$ veraison, respectively. ${ }^{*},{ }^{* *}, * * *$ indicate significance at $p \leq 0.05,0.01,0.001$, respectively. 
treatment having the highest $\mathrm{D} 50 \mathrm{BB}$, and the mean delayed budburst (i.e., deeper dormancy) of V and V20 ABA-treated vines was three days compared to the control (Figure 2B). Later application of ABA at V40 and V55 did not affect bud dormancy (data not shown).

Determination of freezing tolerance. In Wooster, LT50 was not different among treatments during the onset of cold acclimation from September to November 2009 and during deacclimation in March 2010 (Figure 3A). However, the LT50 of V and V30 ABA-treated vines was reduced (i.e., freezing tolerance increased) in December, January, and February by $2.3^{\circ} \mathrm{C}, 2.3^{\circ} \mathrm{C}$, and $1.5^{\circ} \mathrm{C}$, respectively, compared to control vines. Multiple applications did not increase the freezing tolerance on any collection date (data not shown). Similar to the previous dormant season, LT50 was not different among
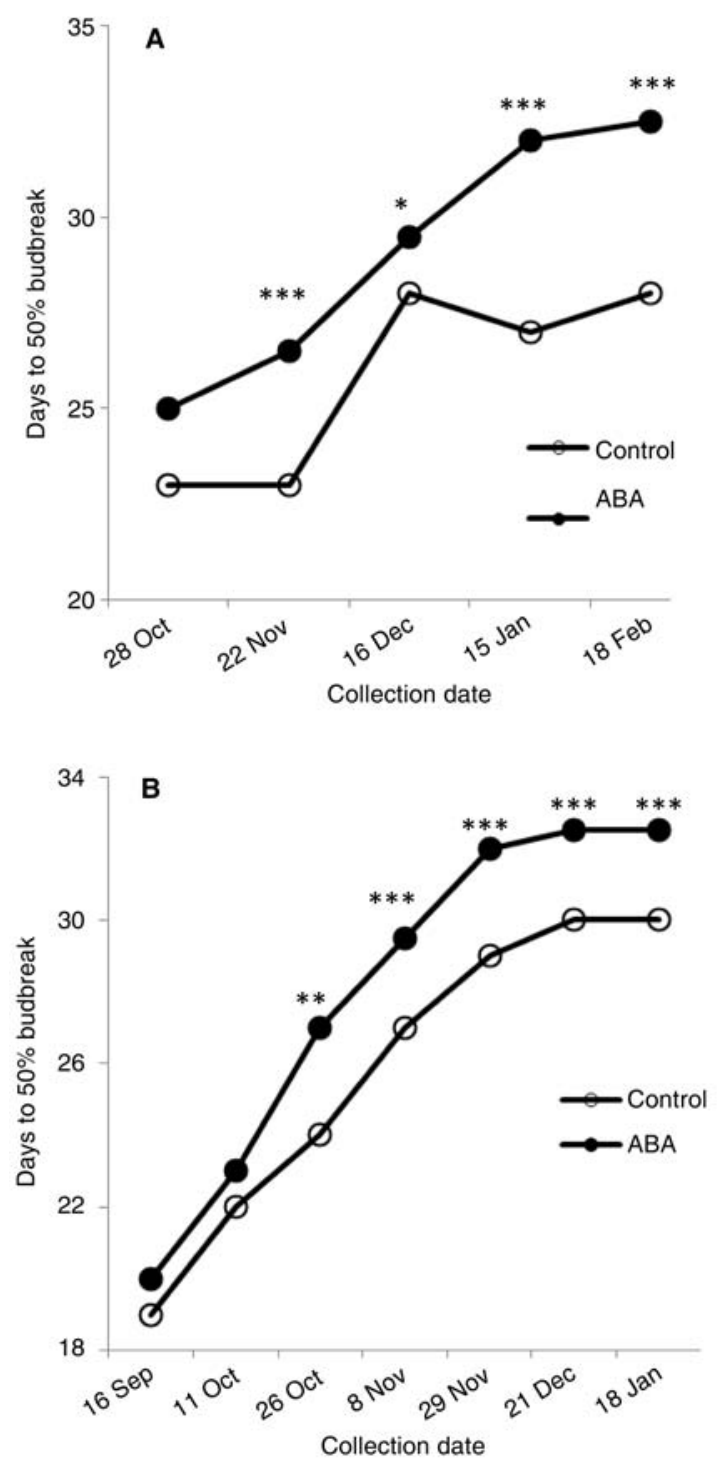

Figure 2 Effect of ABA on bud dormancy (days to $50 \%$ budbreak) of Cabernet franc grapevines grown at (A) Wooster and (B) Kingsville during the 2010-2011 season. For clarity, only one ABA plot is presented, which is the average of $\mathrm{V}$ and V20 treatments (corresponding to ABA aplication at $50 \%$ veraison and 20 days after $50 \%$ veraison). ${ }^{*},{ }^{* \star}$, ${ }^{* \star \star}$ indicate significance at $p \leq 0.05,0.01,0.001$, respectively.
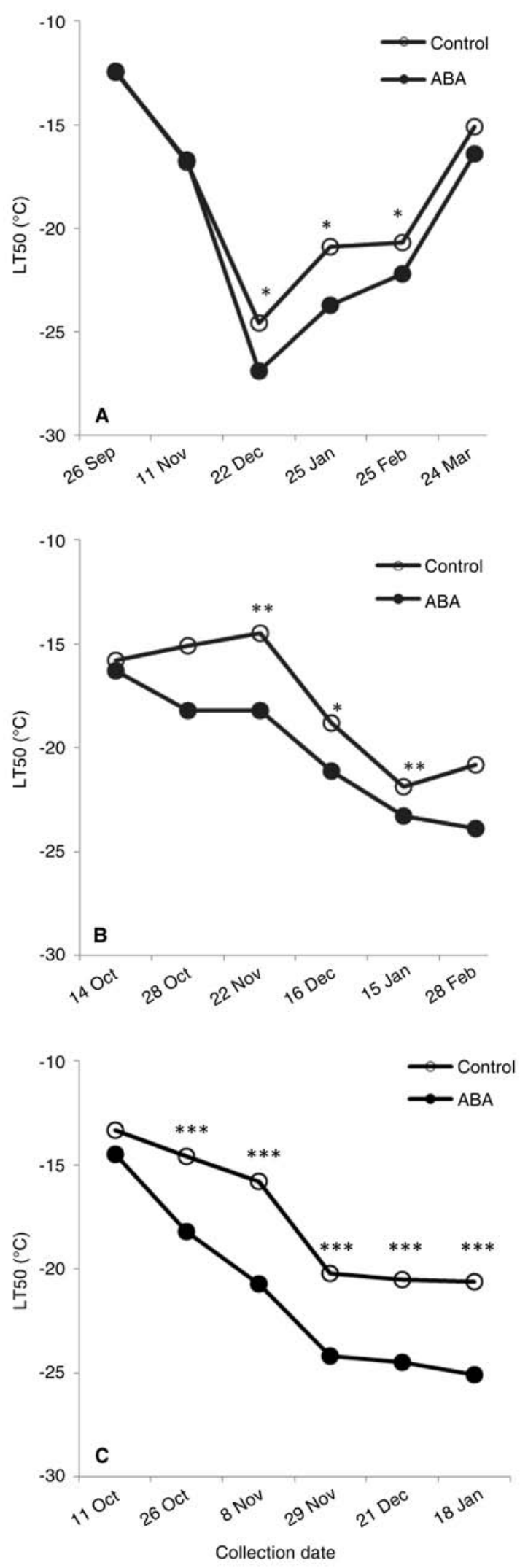

Figure 3 Effect of ABA on freezing tolerance (LT50) in Cabernet franc grapevines grown in Wooster during the (A) 2009-2010 season and the (B) 2010-2011 season and in Kingsville during the (C) 2010-2011 season. For clarity, only treatments with significance are shown. The ABA plot is the average of $\mathrm{V}$ and $\mathrm{V} 30$ in $\mathrm{A}$ and of $\mathrm{V}$ and $\mathrm{V} 20$ in $\mathrm{B}$ and C. (V, V20, and V30 correspond to ABA application at 50\% veraison and 20 and 30 days after $50 \%$ veraison.) ${ }^{*},{ }^{* *}$, ${ }^{* * *}$ indicate significance at $p \leq 0.05,0.01,0.001$, respectively. 
treatments during the first two collections in October 2010 (Figure 3B). However, V and V20 ABA treatments consistently increased the freezing tolerance by $2.7^{\circ} \mathrm{C}$ on average from November 2010 through January 2011. ABA also increased the freezing tolerance of vines treated at V40, but the effect was not consistent (data not shown). In Kingsville, LT50 was not affected on 11 Oct 2010, but were different on all other dates from late October 2010 through 18 Jan 2011. ABA treatment at $\mathrm{V}$ and V20 consistently decreased LT50 (i.e., increased freezing tolerance) by $4.2^{\circ} \mathrm{C}$ on average (Figure 3C). ABA applied later in the season at V40 and V55 did not affect LT50, which was similar to the control (data not shown).

The assessment of bud injury following exposure to $-19^{\circ} \mathrm{C}$ and $-23^{\circ} \mathrm{C}$ showed similar results to those obtained from LT50 determinations. In Wooster, bud injury was relatively low after exposure to $-19^{\circ} \mathrm{C}$, ranging from $13 \%$ to $22 \%$. However, $\mathrm{V}$ and V20 ABA-treated vines sustained less bud injury than the control. In Kingsville, bud injury increased after exposure to $-23^{\circ} \mathrm{C}$ and ranged from $38 \%$ to $66 \%$. V and V20 ABA-treated vines sustained $38 \%$ bud injury, which was much lower than that sustained by control vines (66\%).

Bud water content. We hypothesized that ABA improves freezing tolerance of buds by inducing bud tissue dehydration and hence leading to less freezable water. Results from the Kingsville site indicate that there were no differences in water content in bud and leaf tissues $24 \mathrm{hr}$ after ABA application (data not shown). However, ABA treatments started to affect bud water content on 11 Oct 2010, or 55 days after ABA was applied at V stage. Bud water content in buds from $\mathrm{V}$ and V20 treatments decreased $15 \%$ on average compared to the control (Figure 4). Water content in V40 and V55 treatments was not affected (data not shown). Furthermore, there was a progressive bud dehydration that occurred in all treatments, including the control, from fall through winter, but was further enhanced in V and V20 treatments.

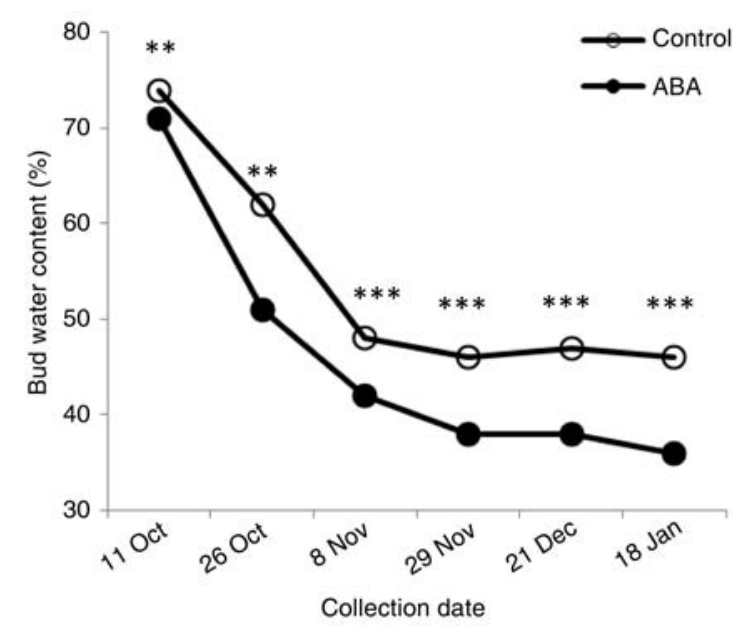

Figure 4 Bud water content (\% FW) progression in ABA-treated and untreated Cabernet franc grapevines grown in Kingsville during the 2010-2011 season. For clarity, the ABA plot represents the average of $\mathrm{V}$ and $\mathrm{V} 20 .{ }^{*},{ }^{* *},{ }^{* * *}$ indicate significance at $p \leq 0.05,0.01,0.001$, respectively.
Correlation analysis. To confirm the hypothesis stated above, correlation analyses were conducted between freezing tolerance and water content in buds. There was a positive correlation $(\mathrm{R}=0.724, p<0.001)$ between freezing tolerance (expressed as LT50) and water content (Figure 5A). This relationship was further supported when bud water content measured on 18 Jan 2011 was compared to bud injury assessed after the freezing event on 22 January 2011, resulting in a strong correlation $(\mathrm{R}=0.834, p<0.001)$ (Figure 5B).

\section{Discussion}

Yield and fruit composition. Optimum ABA rates generally did not affect yield components or the basic juice chemistry. These findings are in agreement with previous work conducted on table grapes in California. It has been reported that ABA slightly increased cluster size, but had no impact on cluster weight or yield when sprayed on clusters of Crimson Seedless at veraison, and there was no evidence of significant differences in Brix, $\mathrm{pH}$, or TA between ABA and control treatments (Lurie et al. 2009).

ABA application has been widely reported to enhance color development in several grapevine cultivars by promoting anthocyanin synthesis and accumulation on berry skins (Peppi et al. 2007). However, the effect of ABA application on anthocyanin accumulation varies among grape cultivars and depends on the type of glucosides and anthocyanins they contain (Kim et al. 1998). Our results agreed with previous findings
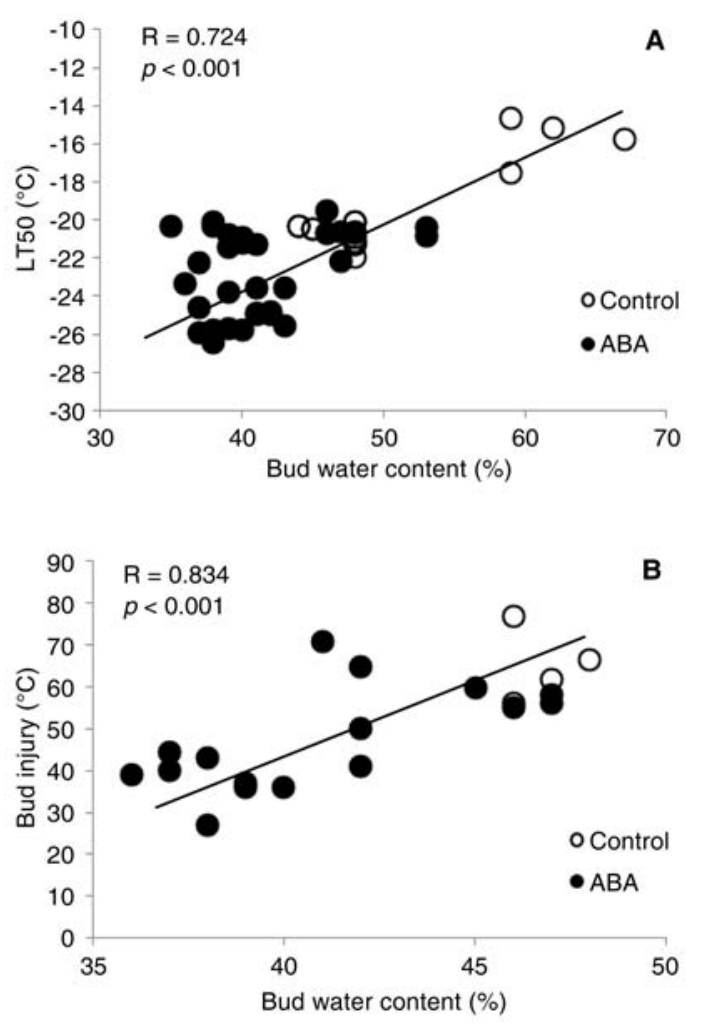

Figure 5 Correlation of (A) LT50 and bud water content from samples collected between 26 Oct 2010 and 18 Jan 2011 in Kingsville; (B) bud injury after $-23^{\circ} \mathrm{C}$ on 22 Jan 2011 vs. water content from samples collected on 18 Jan 2011. ABA values are from V and V20 treatments. 
and showed that ABA application at veraison increased the anthocyanin content of Cabernet franc grapes, indicating that the $\mathrm{V}$ stage is optimal for ABA application to enhance color development. However, when applied postveraison (V20, $\mathrm{V} 30$, or V40), the ABA effect on color was not consistent. It is concluded that ABA has the potential to increase fruit composition attributes (e.g., anthocyanin) in winegrapes even when basic fruit composition remains the same.

Periderm formation and leaf senescence. In a previous greenhouse work, ABA advanced periderm formation in potted Cabernet franc vines (Zhang et al. 2011). However, that was not the case in field-grown Cabernet franc grapevines. It is suggested that field-grown Cabernet franc grapevines started lignification earlier and by the time ABA was applied, lignification was almost complete in all treatments, thus no differences were detected. Furthermore, since field-grown Cabernet franc grapevines were hedged before ABA application, the limited shoot length and internode numbers made it difficult to distinguish the difference among treatments. A field study with Vitis interspecific hybrid Chambourcin, with nonhedged shoots and later lignification, showed advanced periderm formation with ABA and corroborated the greenhouse findings (Zhang and Dami, unpublished data).

A drastic reduction of chlorophyll concentration occurred in early October of both years, indicating a slowdown of photosynthesis and initiation of leaf senescence. In a previous greenhouse study, the reduction of chlorophyll concentration was observed two weeks after ABA was applied to 120-day old leaves and was consistently lower than that of untreated controls, which remained the same (Zhang et al. 2011). Even though it appears that senescence measured by chlorophyll content was triggered after harvest in Wooster, the latter could not be the cause since senescence occurred on vines without a crop (i.e., no harvest trigger) in Kingsville. These findings are in agreement with those from greenhouse-grown and nonbearing Cabernet franc vines (Zhang et al. 2011). The role of ABA on leaf senescence has been investigated in many crop species and it was demonstrated that ABA was translocated from root to shoot and triggered the leaf abscission process (Dong et al. 2008). Furthermore, a link between ABA and leaf senescence has been demonstrated in Arabidopsis thaliana, with up-regulation of two senescence-associated mRNAs, pSEN4 and pSEN5, after exogenous ABA application (Park et al. 1998).

Bud dormancy. Under the forcing conditions used in this dormancy assay protocol, ABA concentrations of 400 and 600 $\mathrm{mg} / \mathrm{L}$ were effective in enhancing dormancy in V20 treated vines compared to the control. These results confirm our findings from a greenhouse study where ABA induced deeper dormancy in potted Cabernet franc vines (Zhang et al. 2011).

ABA-induced bud dormancy development was observed in other woody plants such as Malus domestica (L.) Borkh. (Guak and Fuchigami 2001). In apple, the exogenous application of ABA may have led to an increase in the concentration of endogenous ABA, which was closely related to the extent of dormancy. Concentrations of endogenous ABA increased as grape nodes entered dormancy and were highest at maxi- mum dormancy (Or et al. 2000). ABA was considered as a positive regulator of dormancy induction and maintenance (Kucera et al. 2005). Bud dormancy in woody species, including grapes, is categorized into three different types based on the inhibition sources: in paradormancy, the inhibition is from distal organs; in endodormancy, the inhibition is from internal bud signals; and in ecodormancy, the inhibition is from unfavorable environmental conditions (Lang et al. 1987). In this study, endodormancy was observed, as single cuttings (not paradormant) were used under favorable growing conditions (not ecodormant) and exogenous ABA application induced deeper dormancy. The results of the field trials were consistent with the findings of the greenhouse work (Zhang et al. 2011).

ABA application timing and leaf age. It was previously determined that ABA effectiveness increased when applied on vines with older leaves (Zhang et al. 2011). In fact, ABA induced dormancy responses such as growth cessation, leaf senescence, and abscission on grapevines with leaf age of 80 to 120 days. In this field study, it was demonstrated that the optimum timing for effective foliar ABA application was at veraison and 3 to 4 weeks postveraison. This coincided with leaf age of 120 to 140 days. Based on previous greenhouse studies and the current field studies, we conclude that timing of ABA application is independent of the berry stage of development, but rather depends on leaf age.

The age-related effect of ABA has been explained by the function of an ABA-induced, age-induced gene RPK1 in Arabidopsis, which encodes a receptor kinase (Lee et al. 2011). The conditional overexpression of $R P K 1$ in mature leaves accelerated senescence and cell death and up-regulated various ABA-inducible genes, which indicated the effect of ABA was age-dependent (Lee et al. 2011). However, very old leaves (corresponding to leaf age between 150 and 165 days) may lose sensitivity to exogenous ABA when applied at V40 and V55 stages. Leaves may have already begun the senescence process with the biosynthesis and accumulation of endogenous ABA, limiting the availability of ABA receptors to interact with exogenous ABA.

Freezing tolerance. ABA has been shown previously to increase freezing tolerance of several herbaceous and woody plants including Malus domestica (L.) Borkh. (Guak and Fuchigami 2001) and Secale cereale L. (Churchill et al. 1998). To our knowledge, this is the first report that demonstrates that ABA increased the freezing tolerance of field-grown grapevines (in this case Cabernet franc) based on simulated freezing tests to compute LT50s, confirmed with field assessment of bud injury following a natural freezing event. Bud injury sustained by ABA-treated vines at veraison was reduced by $\sim 40 \%$ compared to control vines exposed to $-19^{\circ} \mathrm{C}$ in Wooster. The percent of bud injury reduction was similar between ABA-treated and control vines even when vines were exposed to a different minimum temperature $\left(-23^{\circ} \mathrm{C}\right)$ and grown at a different location (i.e., Kingsville). These results may be coincidental or may suggest that vines treated with a given ABA concentration at a given stage of development would gain the same level of bud protection in Wooster or 
Kingsville. This finding could potentially allow forecasting the level of damage based on the protection provided by ABA; however, this hypothesis needs further investigation.

\section{Conclusion}

Foliar ABA application at optimal rates (400 or $600 \mathrm{mg} / \mathrm{L}$ ) at 3 to 4 weeks postveraison was effective at inducing increased freezing tolerance and deeper bud dormancy of fieldgrown Cabernet franc. ABA application also promoted anthocyanin accumulation in grape berries, which is a desirable fruit composition attribute. The finding that exogenous ABA application has the capacity to induce a deeper dormancy status and increase freezing tolerance is beneficial to grapegrowers and may be used as a prophylactic tool to protect against winter injury of cold-sensitive grape cultivars grown in cold regions.

\section{Literature Cited}

Churchill, G.C., M.J.T. Reaney, S.R. Abrams, and L.V. Gusta. 1998. Effects of abscisic acid and abscisic acid analogs on the induction of freezing tolerance of winter rye (Secale cereale L.) seedlings. Plant Growth Regul. 25:35-45.

Dami, I.E., and B.A. Beam. 2004. Response of grapevines to soybean oil application. Am. J. Enol. Vitic. 55:269-275.

Dami, I.E., S. Ennahli, and Y. Zhang. 2012. Assessment of winter injury in grape cultivars and pruning strategies following a freezing stress event. Am. J. Enol. Vitic. 63:106-111.

Dong, H., Y. Niu, W. Li, and D. Zhang. 2008. Effects of cotton rootstock on endogenous cytokinins and abscisic acid in xylem sap and leaves in relation to leaf senescence. J. Exp. Bot. 59:1295-1304.

Eichhorn, K.W., and D.H. Lorenz. 1977. Phenological development stages of the grapevine. Nachrichtenbl. Dt. Pflanzenschutzd. 29:119-120.

Giusti, M., L. Rodriguez-Saona, and R. Wrolstad. 1999. Molar absorptivity and color characteristics of acylated and non-acylated pelargonidin-based anthocyanins. J. Agric. Food Chem. 47:4631-4637.

Guak, S., and L.H. Fuchigami. 2001. Effects of applied ABA on growth cessation, bud dormancy, cold acclimation, leaf senescence and $\mathrm{N}$ mobilization in apple nursery plants. J. Hortic. Sci. Biotechnol. 76:459-464.

Hellman E., S. Shelby, and C. Lowery. 2006. Exogenously applied abscisic acid did not consistently delay budburst of deacclimating grapevine. J. Am. Pomol. Soc. 60:178-186.

Jeong, S.T., N. Goto-Yamamoto, S. Kobayashi, and A. Esaka. 2004. Effects of plant hormones and shading on the accumulation of anthocyanins and the expression of anthocyanin biosynthetic genes in grape berry skins. Plant Sci. 167:247-252.

Ju, Z., and L. Howard. 2003. Effects of solvent and temperature on pressurized liquid extraction of anthocyanins and total phenolics from dried red grape skin. J. Agric. Food Chem. 51:5207-5213.

Kim, S., J. Kim, S. Jeon, Y. Nam, and S. Kim. 1998. Effects of ethephon and $\mathrm{ABA}$ application on coloration, content, and composition of anthocyanin in grapes (Vitis spp.). J. Korean Soc. Hortic. Sci. 39:547-554.

Kucera, B., M.A. Cohn, and G. Leubner-Metzger. 2005. Plant hormone interactions during seed dormancy release and germination. Seed Sci. Res. 15:281-307.

Kumar, S., G. Kaur, and H. Nayyar. 2008. Exogenous application of abscisic acid improves cold tolerance in chickpea (Cicer arietinum L.). J. Agron. Crop Sci. 194:449-456.

Lang, G.A., J.D. Early, G.C. Martin, and R.L. Darnell. 1987. Endodormancy, paradormancy, and ecodormancy-Physiological terminology and classification for dormancy research. HortScience 22:371-377.

Lee, I.C., S.W. Hong, S.S. Whang, P.O. Lim, H.G. Nam, and J.C. Koo. 2011. Age-dependent action of an ABA-inducible receptor kinase, RPK1, as a positive regulator of senescence in Arabidopsis leaves. Plant Cell Physiol. 52:651-662.

Llorente, F., J. Oliveros, J. Martinez-Zapater, and J. Salinas. 2000. A freezing-sensitive mutant of Arabidopsis, frs1, is a new aba3 allele. Planta 211:648-655

Lurie, S., R. Ovadia, A. Nissim-Levi, M. Oren-Shamir, T. Kaplunov, Y. Zutahy, H. Weksler, and A. Lichter. 2009. Abscisic acid improves colour development in 'Crimson Seedless' grapes in the vineyard and on detached berries. J. Hortic. Sci. Biotechnol. 84:639-644.

Or, E., E. Belausov, I. Popilevsky, and Y. Ben Tal. 2000. Changes in endogenous ABA level in relation to the dormancy cycle in grapevines grown in a hot climate. J. Hortic. Sci. Biotechnol. 75:190-194.

Park, J.H., S.A. Oh, Y.H. Kim, H.R. Woo, and H.G. Nam. 1998. Differential expression of senescence-associated mRNAs during leaf senescence induced by different senescence-inducing factors in Arabidopsis. Plant Mol. Biol. 37:445-454.

Peppi, M.C., M.W. Fidelibus, and N.K. Dokoozlian. 2007. Application timing and concentration of abscisic acid affect the quality of 'Redglobe' grapes. J. Hortic. Sci. Biotechnol. 82:304-310.

Poling, E.B. 2007. Overview of active frost, frost/freeze and freeze protection methods. In Understanding and Preventing Freeze Damage in the Vineyard Workshop Proceedings, pp. 47-64. University of Missouri Extension, Columbia.

Wake, C., and A. Fennell. 2000. Morphological, physiological and dormancy responses of three Vitis genotypes to short photoperiod. Physiol. Plantarum 109:203-210.

Wolf, T.K., and R.M. Pool. 1987. Factors affecting exotherm detection in the differential thermal-analysis of grapevine dormant buds. J. Am. Soc. Hortic. Sci. 112:520-525.

Xiao, H., M. Siddiqua, S. Braybrook, and A. Nassuth. 2006. Three grape $\mathrm{CBF} / \mathrm{DREB} 1$ genes respond to low temperature, drought and abscisic acid. Plant Cell Environ. 29:1410-1421.

Zabadal,T., I. Dami, M. Goffinet, T. Martinson, and M. Chien. 2007. Winter injury to grapevine and methods of protection. Michigan State University Extension, East Lansing.

Zhang, Y., T. Mechlin, and I. Dami. 2011. Foliar application of abscisic acid induces dormancy responses in greenhouse-grown grapevines. HortScience 46:1271-1277. 